\title{
Whole Grain Intakes in Irish Pre-school Children
}

\author{
C. Hamrock ${ }^{1}$, M. Buffini ${ }^{1}$, A.P. Nugent ${ }^{1,2}$, J. Walton ${ }^{3}$, A. Flynn ${ }^{3}$, and B.A. McNulty ${ }^{1}$ \\ ${ }^{1}$ UCD Institute of Food and Health, University College Dublin, Ireland; ${ }^{2}$ Institute for Global Food Security, Queens University Belfast, ${ }^{3}$ School of \\ Food and Nutritional Sciences, University College Cork, Ireland
}

\section{Introduction}

Whole grain intakes are associated with reduced risk for chronic diseases such as type 2 diabetes, cardiovascular disease and colorectal cancer ${ }^{(1,2)}$. Pre-school is a critical developmental stage where taste preferences are established thus stressing the importance of early healthy food introduction such as whole grain ${ }^{(3)}$. Therefore the aim of the current study is to determine whole grain intakes and profile consumption patterns in Irish Pre-school children.

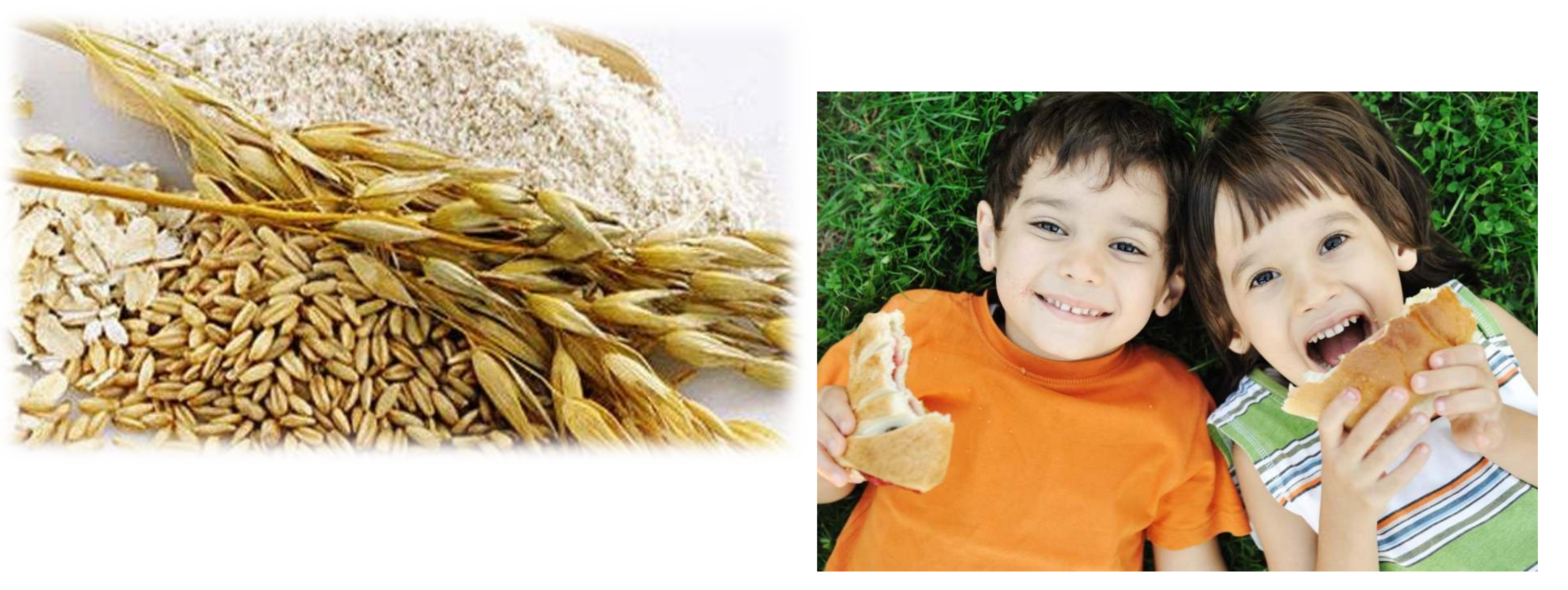

Materials \& Methods

Habitual whole grain intakes were assessed using 4-day weighed intake diaries from 1-4 year olds ( 500) from the National Pre-school Nutrition Survey (NPNS). The presence of whole grain was determined using food package labelling, comparable products and recipe databases specific for the NPNS. Whole grain content was calculated as dry matter, whereby the water content (\%) and the dry matter whole grain content (\%) of whole grain ingredients were established. Dietary intakes of whole grain were explored between age and gender by independent t-tests and ANOVA using SPSS version 20.0 (IBM Inc. Chicago, USA).

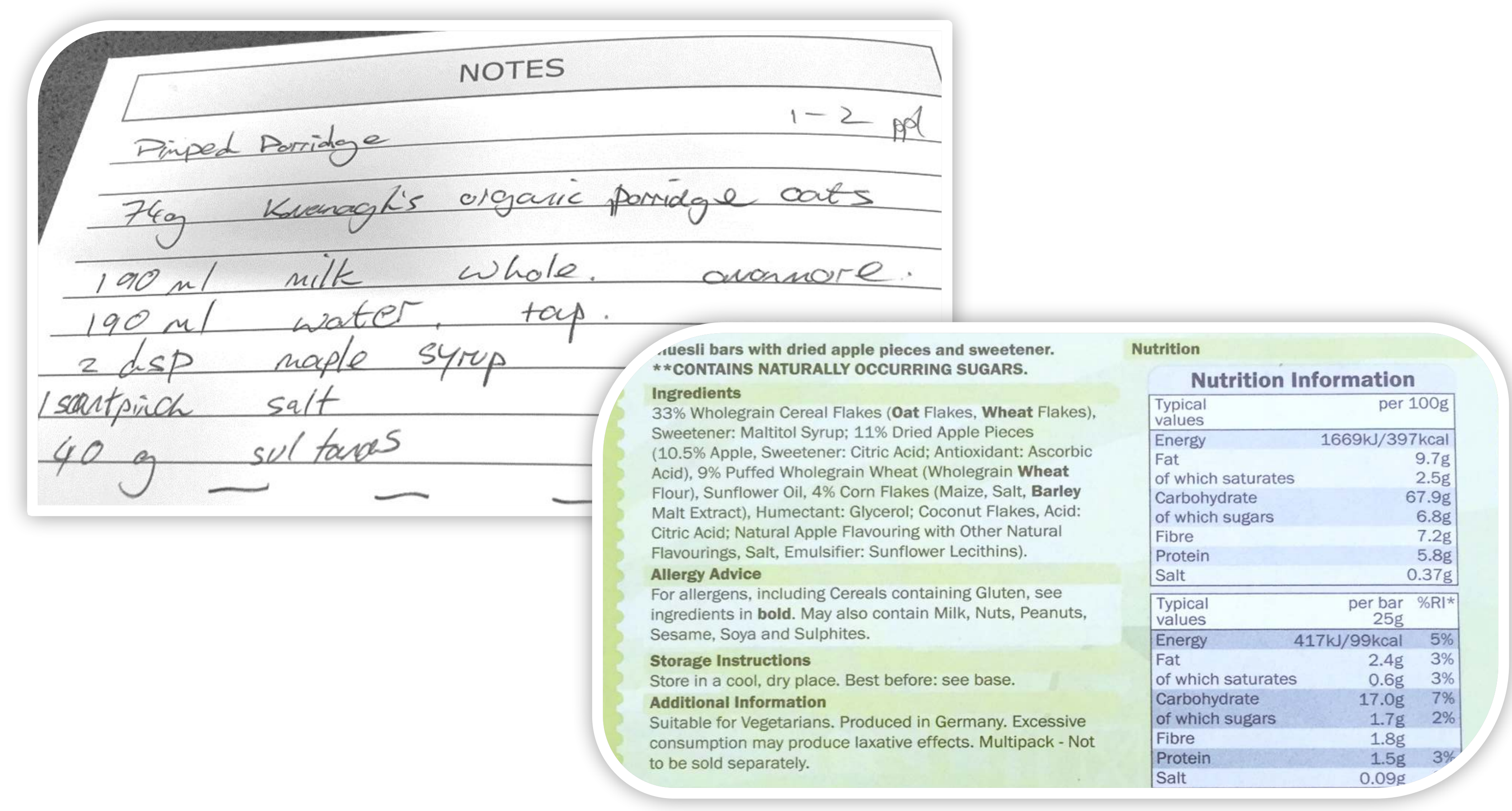

\section{Results}

$97 \%$ of pre-school children were whole grain consumers, with mean consumption of total population being $18 \mathrm{~g} / \mathrm{d}$, rising to $19 \mathrm{~g} / \mathrm{d}$ amongst consumers only. However the range of intakes was vast, with a $1.4-51 \mathrm{~g} / \mathrm{d}$ range between the $5^{\text {th }}$ and $97.5^{\text {th }}$ percentile. Wheat sources provided the largest contribution to whole grain intakes $(66 \%)$, followed by oats $(21 \%)$. The primary food group contributors to whole grain intakes were 'Ready-to-eat breakfast cereals' (50\%), followed by 'bread and rolls' (24\%). Correspondingly, breakfast had the highest number of whole grain consumers (92\%). High consumers of whole grain had significantly higher intakes of fibre, iron, vitamin B12 and folate, and lower intakes of sodium $(\mathrm{p}<0.05)$.

\begin{tabular}{|c|c|c|c|c|c|c|c|c|}
\hline & $n$ & $\%$ & Mean & Median & SD & P5.0 & P97.5 & $\mathrm{P}$ \\
\hline Total Population & 500 & 100 & 18.4 & 16.1 & 13.4 & 1.4 & 50.7 & \\
\hline Gender & & & & & & & & 0.051 \\
\hline Male & 251 & 50.2 & 19.6 & 16.7 & 14.5 & 1.6 & 57.5 & \\
\hline Female & 249 & 49.8 & 17.7 & 15.4 & 12.0 & 0.4 & 48.0 & \\
\hline Age & & & & & & & & 0.031 \\
\hline 1 Year & 126 & 25.2 & $16.1^{a}$ & 13.9 & 11.3 & 2.1 & 50.9 & \\
\hline 2 Years & 124 & 24.8 & $18.1^{\mathrm{ab}}$ & 16.6 & 12.0 & 1.3 & 48.0 & \\
\hline 3 Years & 126 & 25.2 & $18.6^{\mathrm{ab}}$ & 15.5 & 13.7 & 1.4 & 53.2 & \\
\hline 4 Years & 124 & 24.8 & $21.1^{b}$ & 18.5 & 15.7 & 0.6 & 60.9 & \\
\hline
\end{tabular}

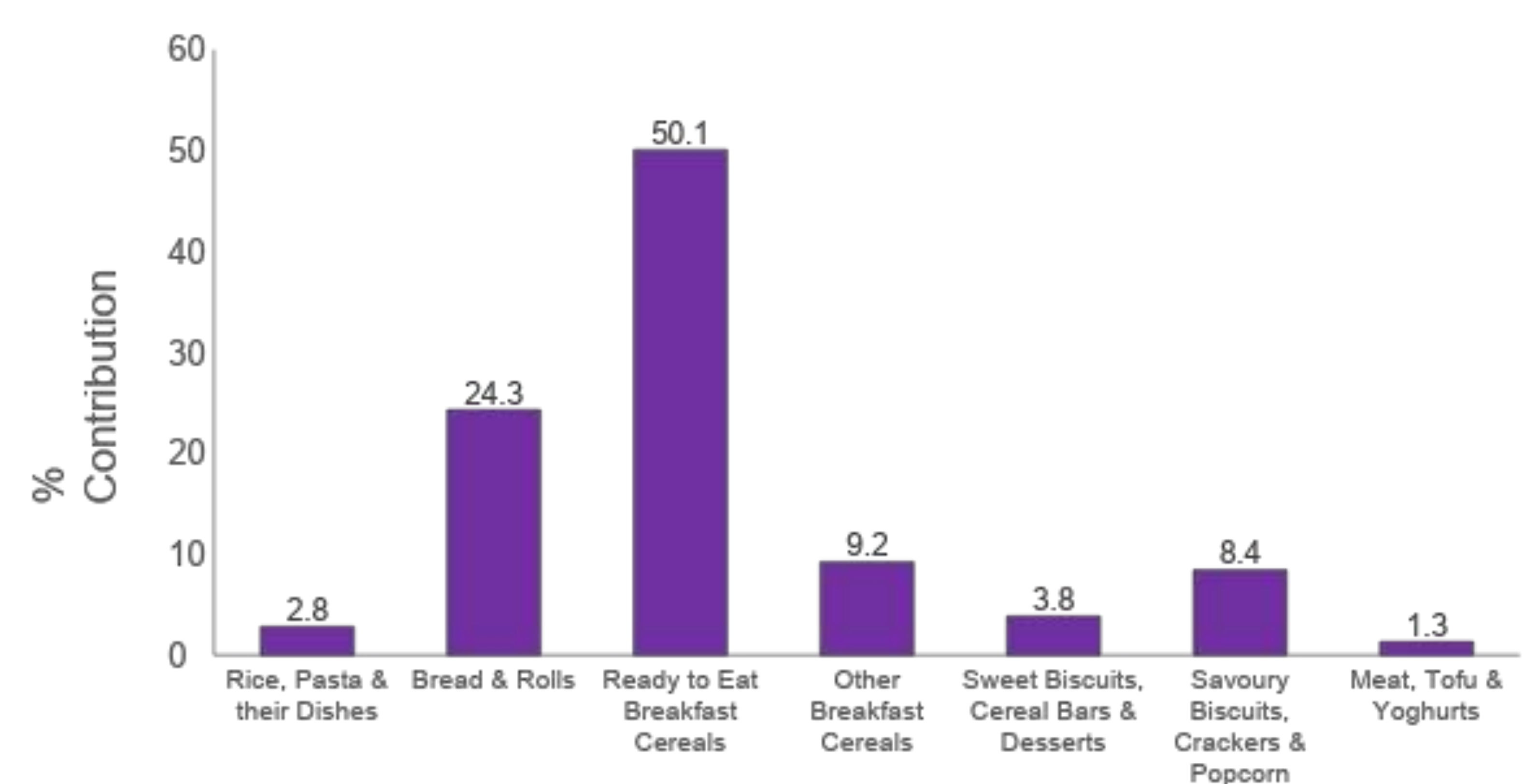

Percentage contribution of whole grain food groups to overall whole grain intakes

\section{Discussion \& Conclusion}

The present study shows that while a high proportion of pre-school children are whole grain consumers, overall dietary intakes are low. Development of an applicable quantitative recommendation is necessary for this age group as currently none exists.

\section{References}

1. Wu H, Flint AJ, Qi Q et al. (2015) JAMA Intern Med 175(3):373-84. 2. Schatzkin A, Mouw T, Park Y et al. (2007) Am J Clin Nutr 85(5):1353-60. 3. Cooke L (2007) J Hum Nutr Diet 20(4):294-301

\section{Acknowledgements:}

The project was funded by the Department of Agriculture Fisheries and Food, and Health Research Board under the Food for Health Research Initiative 2007-2012

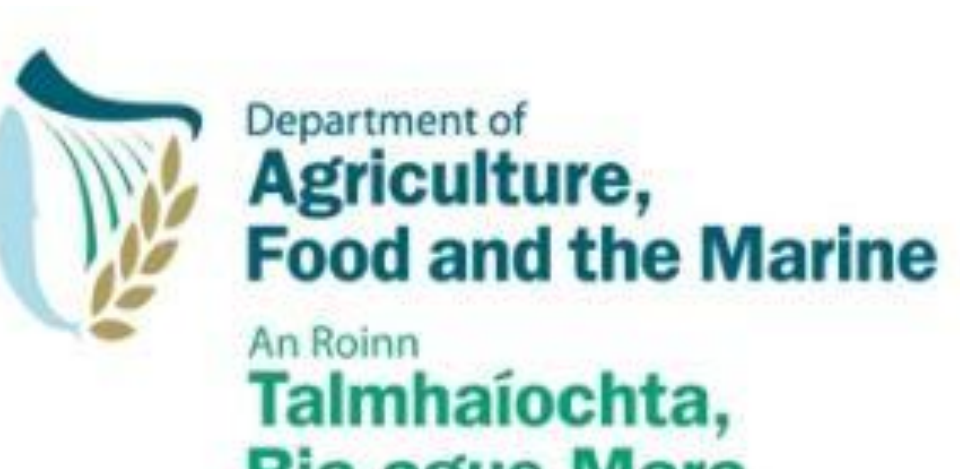
Bia agus Mara 